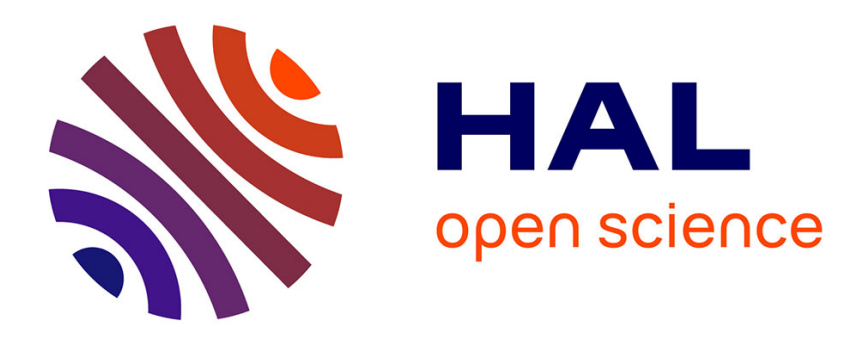

\title{
Effects of nanoparticles in gills and hepatopancreas - a new threat to marine life?
}

Angela Koehler, Ute Marx, Katja Broeg, Sieglinde Bahns, Jana Bressling

\section{To cite this version:}

Angela Koehler, Ute Marx, Katja Broeg, Sieglinde Bahns, Jana Bressling. Effects of nanoparticles in gills and hepatopancreas - a new threat to marine life?. Marine Environmental Research, 2008, 66 (1), pp.12. 10.1016/j.marenvres.2008.02.009 . hal-00501941

\section{HAL Id: hal-00501941 https://hal.science/hal-00501941}

Submitted on 13 Jul 2010

HAL is a multi-disciplinary open access archive for the deposit and dissemination of scientific research documents, whether they are published or not. The documents may come from teaching and research institutions in France or abroad, or from public or private research centers.
L'archive ouverte pluridisciplinaire HAL, est destinée au dépôt et à la diffusion de documents scientifiques de niveau recherche, publiés ou non, émanant des établissements d'enseignement et de recherche français ou étrangers, des laboratoires publics ou privés. 


\section{Accepted Manuscript}

Effects of nanoparticles in Mytilus edulis gills and hepatopancreas - a new threat to marine life?

Angela Koehler, Ute Marx, Katja Broeg, Sieglinde Bahns, Jana Bressling

PII:

S0141-1136(08)00025-1

DOI:

10.1016/j.marenvres.2008.02.009

Reference:

MERE 3177

To appear in:

Marine Environmental Research

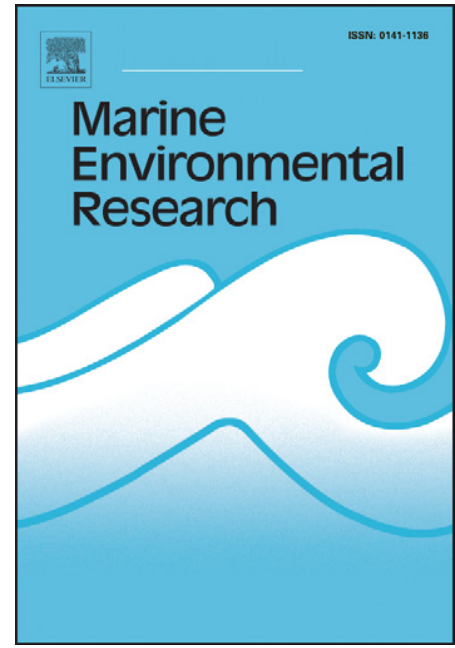

Please cite this article as: Koehler, A., Marx, U., Broeg, K., Bahns, S., Bressling, J., Effects of nanoparticles in Mytilus edulis gills and hepatopancreas - a new threat to marine life?, Marine Environmental Research (2008), doi: 10.1016/j.marenvres.2008.02.009

This is a PDF file of an unedited manuscript that has been accepted for publication. As a service to our customers we are providing this early version of the manuscript. The manuscript will undergo copyediting, typesetting, and review of the resulting proof before it is published in its final form. Please note that during the production process errors may be discovered which could affect the content, and all legal disclaimers that apply to the journal pertain. 


\title{
Effects of nanoparticles in Mytilus edulis gills and hepatopancreas
}

\author{
- a new threat to marine life?
}

\author{
Angela Koehler *, Ute Marx, Katja Broeg, Sieglinde Bahns, Jana Bressling \\ Department of Biosciences, Alfred Wegener Institute for Polar and Marine Research, Germany
}

\begin{abstract}
Every day new extraordinary properties of nanoparticles (a billionth of a meter) are discovered and worldwide millions are invested into nanotechnology and nanomaterials. Risks to marine organisms are still not fully understood and biomarkers to detect health effects are not implemented, yet. We used the filter feeding blue mussel as a model to analyse uptake and effects of nanoparticles from glass wool, a new absorbent material suggested for use in floating oil spill barriers. In both, gills and hepatopancreas we analysed uptake of nanomaterials by transmission electronmicroscopy (TEM) in unstained ultrathin sections over a period of up to 16 days. Lysosomal stability and lipofuscin content as general indicators of cellular pathology and oxidative stress were also measured. As portals of uptake, diffusion and endocytosis were identified resulting in nanoparticle accumulation in endocytotic vesicles, lysosomes, mitochondria and nuclei. Dramatic decrease of lysosomal membrane stability occurred after $12 \mathrm{~h}$ of exposure. Lysosomal damage was followed by excessive lipofuscin accumulation indicative of severe oxidative stress. Increased phagocytosis by granulocytes, autophagy and finally apoptosis of epithelial cells of gills and primary and secondary digestive tubules epithelial cells indicated progressive cell death. These
\end{abstract}


pathological responses are regarded as general indices of toxic cell injury and oxidative stress. By the combinational use of biomakers with the ultrastructural localisation of nanoparticle deposition, final evidence of cause-effect relationships is delivered.

Keywords: Nanoparticles; Marine mussel ; Subcellular accumulation ; Lysosomal pathology

*Corresponding author: Email address: Angela.Koehler@awi.de

Man-made nanoparticles are introduced into the environment from multi-tons of carbon black and fumed silica for plastic fillers, car tyres and house insulation, kilograms in sunscreens, toothpaste, cosmetics, sanitary ware coatings, antifouling covers to micrograms as fluorescent quantum dots in biological imaging (Hoet et al., 2004). According to the EU Scientific Committee on Emerging and Newly Identified Health Risks (SCENIHR, 2005) toxicological risk assessments of nanoparticles should be based on particle size and shape (nanotubes, nanofibre and nanodust such as glass wool and asbestos). Relevant areas to be considered are here: (1) Release of free form nanoparticles in the air or water during production (or production accidents, waste during production) with ultimate accumulation in the soil, water or plant life. (2) In fixed form, as part of a manufactured substance or product, to be recycled or disposed of as waste. Nanoparticles and fibres are classified as fine $(\sim 200$ $\mathrm{nm})$ and ultrafine nanoparticles $(\sim<20-100 \mathrm{~nm})$. As portals of nanoparticle entry into cells, biological membranes contain either few large sized pores (400-nm pore radius), an intermediate number $(30 \%)$ of medium-sized pores (40-nm pore radius) and a very large number (68\%) of small-sized pores (1.3-nm pore radius) (Hoet et al., 2004).

As nanoparticles essentially differ from other environmental toxins, known mechanisms of toxicity do not apply and specific biomarkers have not been developed until 
now (Donaldson et al. 2004; Moore, 2006) and only few studies have been performed in aquatic animals (Lovern and Klaper, 2006). As glass wool has been recently suggested as highly efficient absorptive material for floating oil spill barriers, we exposed the blue mussel Mytilus edulis to beds of untreated glass wool (silicon dioxide; 3-7 $\mu \mathrm{m}$ length, 0.18-1 $\mathrm{m}$ corresponding to respirable size for mammals, dust forming) as a toxicological base line study for further product development. Exposed mussel (n=5 each, 12h, 1d, 2d, 4d, 8d and 16 $\mathrm{d}$ in two parallel experiments) were compared to unexposed mussel kept in same type of aquaria and in the institute's seawater circulation system, sampled in parallel. By transmission electron microscopic studies, we analysed whether and at which size and shapes glass wool nanoparticles were taken up by gills and into hepatopancreas. For this purpose small tissue pieces were fixed in $5 \%$ glutaraldehyde in Sörensen's buffer, and 2\% osmium, and epon embedded. Uncontrasted ultrathin sections were screened for nanoparticle localisation and size range with a Zeiss TEM 109 attached to a SIS Image Analysis System (Münster, Germany). Uptake routes and nanoparticle deposition were related to cellular and subcellular pathologies. As general biomarkers of toxic cell injury and oxidative stress we measured lysosomal membrane stability and lipofuscin in hepatopancreas of same individuals in shock frozen tissue samples (Viarengo et al., 2007). In addition, we analysed the general portals of glass wool intake into the digestive gland by visualising the nanoparticles in cryostat sections by a specific silicon dye, FITC-APS according to Hodson et al. (1994).

Electronmicroscopy, in fact, evidenced that glass particles were taken up in both, the epithelial cells of gills and digestive tubules. Inside of gill epithelial cells larger fibrils were more often found than in hepatopancreas which corresponds to the fact that materials are first sorted and transported at the gills. Pathways of uptake were either by diffusion $(<5 \mathrm{~nm})$ or by endocytosis (5-25 $\mathrm{nm}$ and larger fibres) depending on their size. Unstained ultrathin sections showed that in gills glass ultrafine and fine nanoscale fibres and particle were taken up via the cilia. In general, lysosomes contained the ultrafine particles and, in addition, few 
larger fine crystal-like fibre of a length of up to 125 - $200 \mathrm{~nm}$ were found as shown in Figure 1a in gills. Entry into the tubular system of the hepatopancreas occurred via both cilia and microvilli. Ultrafine nanoparticles of $5-10 \mathrm{~nm}$ in diameter were able to diffuse into mitochondria (also Fig. 1A) whereas only ultrafine nanoparticles of a diameter of smaller than $7 \mathrm{~nm}$ were able to enter into the nucleus. In both tissues, small endocytotic vesicles packed with nanoparticles fused to larger endosomes with nanomaterials of various sizes $(<5-9 \mathrm{~nm}$ nanoparticles; up $60 \mathrm{~nm}$ small fibres) and finally with lysosomes (for overview see hepatopancreas in Figure 1B and details in Figure 1C). Continuous uptake of nanomaterials over the experimental period resulted in large aggregates of lysosomes crowded with ingested nanoparticles and finally apoptosis. Lysosomal stability in tubules decreased significantly from median values of $35 \mathrm{~min}$ in both controls down to values below 10 min already after $12 \mathrm{~h}$ of exposure and remained low until day 16 (Figure 2). Excessive lipofuscin accumulation indicative for oxidative stress was found in epithelial cells of tubules (Fig. 1d and e) as demonstrated by the Schmorl's reaction. Oxidative stress was induced in epithelial cells of gills and tubules themselves and by inflammatory responses of phagocytotic cell (macrophages and granulocytes) attracted by the nanoparticles in the connective storage tissue around the tubules. These findings are in accordance to observations during nanoparticle inhalation in rats (Warheit et al., 2003).

When observing the glass wool uptake by fluorescent imaging (FITC-APS) we found that numerous glass particles of various size up to $7 \mu \mathrm{m}$ accumulated at first in the stomach at the crystal style and only small and fine particles entered in primary tubules after $12 \mathrm{~h}$ and appeared finally in the secondary tubules after 24 hours. The electronmicroscopic results in combination with standardised biomarkers of cell injury and oxidative stress evidenced that certain kinds of nanoparticles may imply, in fact, a non-negligible risk to marine organisms. 


\section{ACCEPTED MANUSCRIPT}

\section{References}

Donaldson, K., Stone, V., Tran, C. L., Kreyling, W., and Borm, P.J.A. (2004). Occupational Environmental Medicine, 61, 727-728.

Hodson, M.J., Smith, R.J., van Blaaderen, A., Crafton, T., and O’Neill, C.H. (1994). Annals of Occupational Hygiene, 38, 149-160.

Hoet, P.H.M., Brüske-Hohlfeld, I., and Salata, O.V. (2004). Journal of Nanobiotechnology, $2,12$.

Lovern, S., and Klaper, R. (2006). Environmental Toxicology and Chemistry, 25, 4, 11321137.

Moore, M.N. (2006). Environment International, 32, 967-976.

SCENIHR. (2005). Scientific Committee on emerging and newly identified health risks.

European Commission Health and Consumer Protection Directorate-general. pp78.

Viarengo, A., Lowe, D., Bolognesi, C. Fabbri, E., Koehler, A. (2007) Comparative Biochemistry and Physiology, Part C, 146, 281-300.

Warheit, D.B., Laurence, B.R., Reed, K.L., Roach, D.H., Reynolds, G.A., and Webb, T.R. (2003). Toxicological Sciences, 77, 117-125. 


\section{Figure captions}

Fig.1. Uptake and effects of nanoparticles of glass wool in Mytilus edulis gill and hepatopancreas. (A) uptake of nanofibrils (large arrow) into gill lysosomes and ultrafine nanoparticles (small arrow) into mitochondria after 12 h, 12000x. (B) Epithelial cells of digestive tubules engulfing particles via endocytotic vesicle (small arrow) and lysosomes (large arrow), 3000x and; (C) Forming large nanoparticle-filled endosomes (arrows) after $24 \mathrm{~h}$ exposure 20000x. d) Cryostat section of hepatopancreas of a control mussel after 16 days stained for lipofuscin and e) and after 16 days of nanoparticle exposure with severe lipofuscin accumulation in digestive tubules and in phagocytes (arrows), both 400x magnification.

Fig. 2. Lysosomal membrane stability (min) during exposure to glass wool over a period of 16 days. Controls were performed in the seawater circulation system and in glass aquaria over the whole period of time (data only shown for the start of the experiment) and each 2 replicates of exposed animals on glass wool. 


\section{ACCEPTED MANUSCRIPT}

Figure 1.
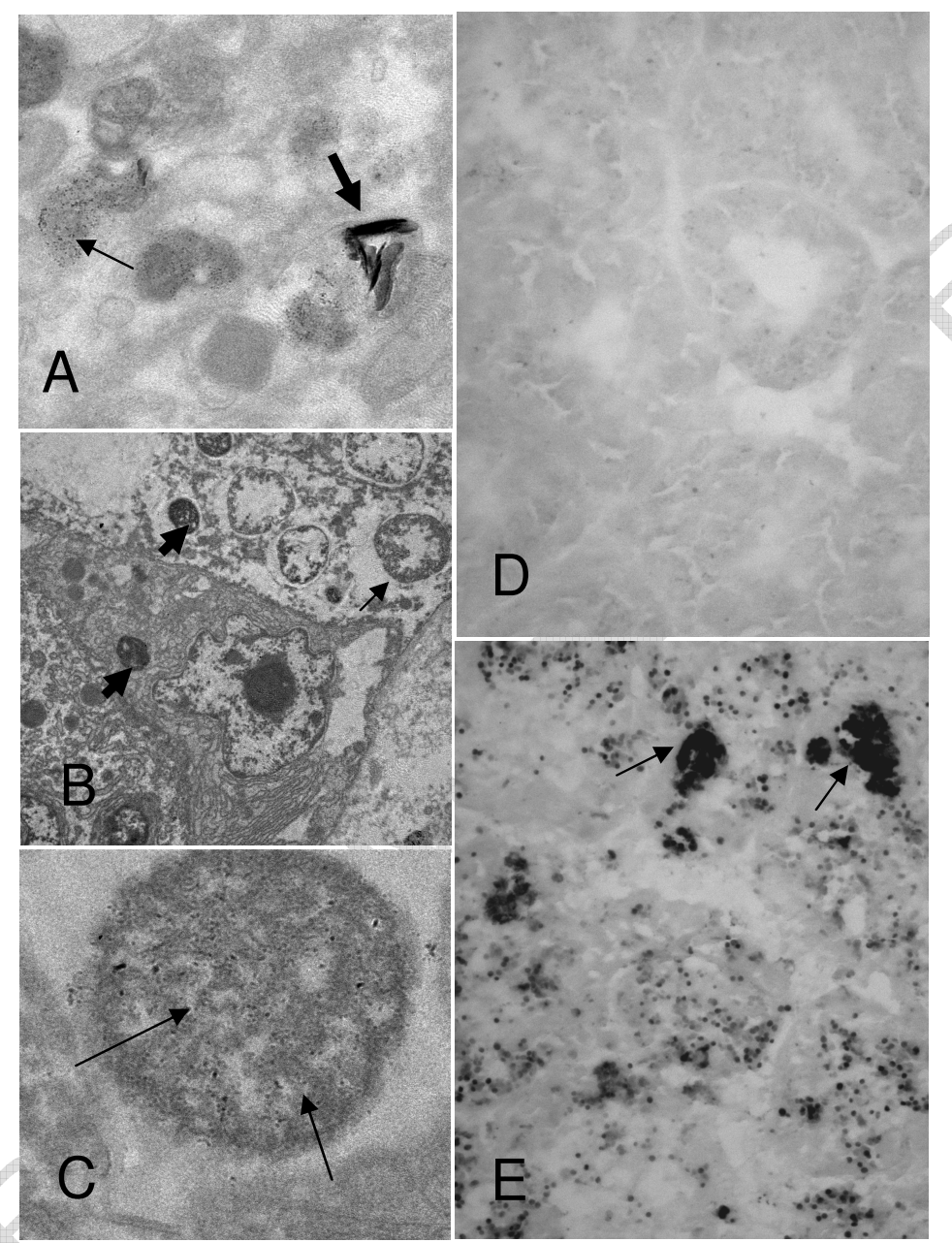
Figure 2.

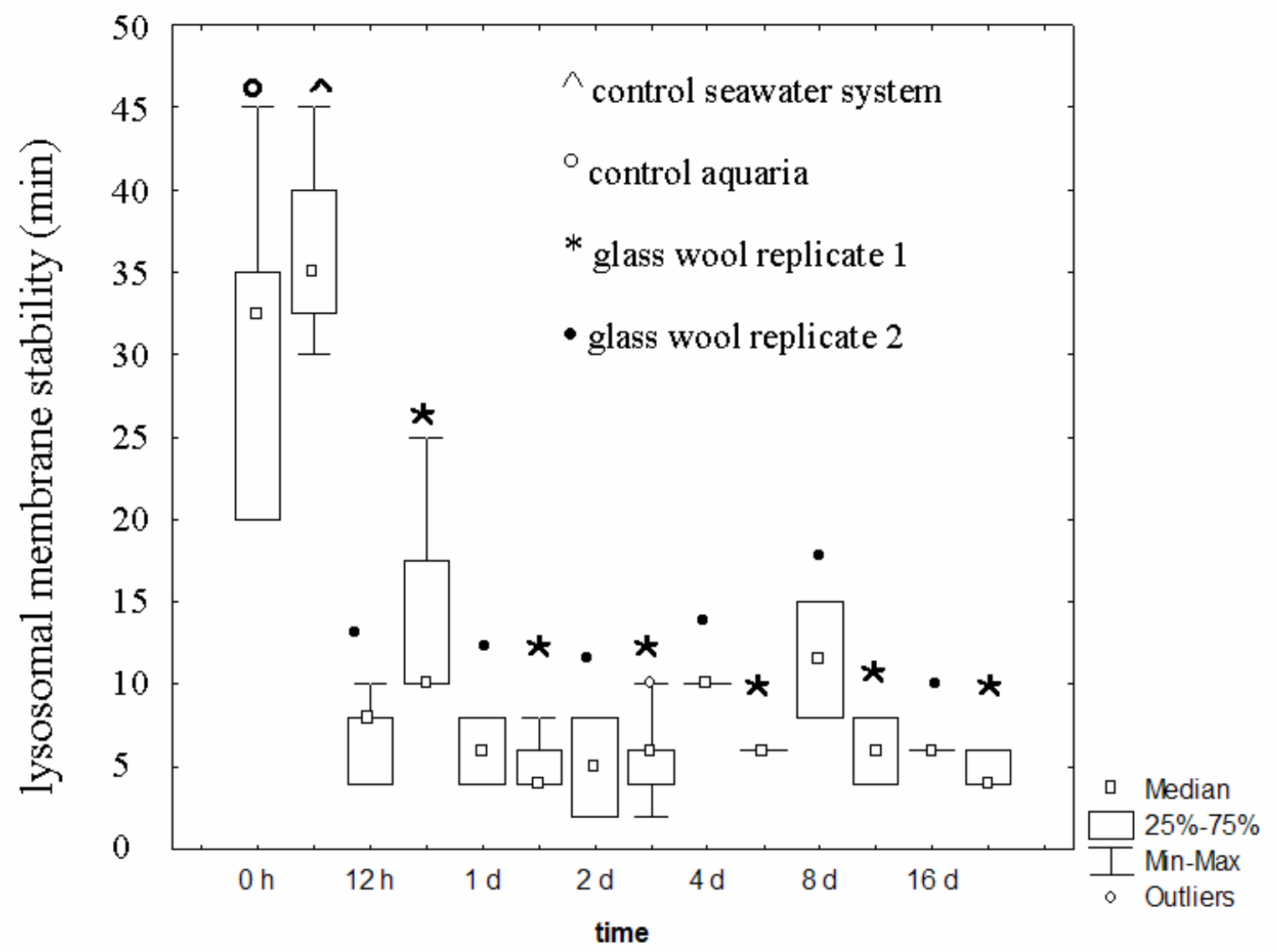

